\title{
Management of iatrogenic flat-back syndrome
}

\author{
Gregory C. Wiggins, M.D., StePhen L. Ondra, M.D., \\ AND Christopher I. ShAFFREY, M.D.
}

Department of Neurological Surgery, David Grant Medical Center, Travis Air Force Base,
California; Department of Neurological Surgery, Northwestern University Medical School, Chicago,
Illinois; and Department of Neurological Surgery, University of Washington, Seattle, Washington

\begin{abstract}
Iatrogenic loss of lordosis is now frequently recognized as a complication following placement of thoracolumbar instrumentation, especially with distraction instrumentation. Flat-back syndrome is characterized by forward inclination of the trunk, inability to stand upright, and back pain. Evaluation of the deformity should include a full-length lateral radiograph obtained with the patient's knees and hips fully extended. The most common cause of the deformity includes the use of distraction instrumentation in the lumbar spine and pseudarthrosis.

Surgical treatment described in the literature includes opening (Smith-Petersen) osteotomy, polysegmental osteotomy, and closing wedge osteotomy. The authors will review the literature, cause, clinical presentation, prevention, and surgical management of flat-back syndrome.
\end{abstract}

\section{KEY WORDS • iatrogenic • flat-back syndrome • deformity • osteotomy • kyphosis • surgery}

Iatrogenic loss of lordosis is now frequently recognized as a complication following placement of thoracolumbar instrumentation, especially with distraction instrumentation spanning the lumbar spine. ${ }^{1,38,39,41,42,54}$ When lumbar lordosis is diminished enough to create an imbalance with the center of gravity of the head anterior to the sacrum it is described as positive sagittal balance. Historically, loss of lumbar lordosis resulted from the use of distraction instrumentation across the lumbar spine in the treatment of scoliosis. Over time, this loss of lumbar lordosis and loss of the ability of other spinal segments to compensate resulted in progressive positive sagittal balance. The symptom complex that develops as the body's compensatory mechanisms fail has been called flat-back syndrome. More recently, the term flat-back syndrome has been used to describe symptoms resulting from iatrogenic loss of lumbar lordosis with forward inclination of the trunk, inability to stand upright, and back pain. We will review the literature, cause, clinical presentation, prevention, and surgical management of flat-back syndrome.

\section{REVIEW OF THE LITERATURE}

Doherty ${ }^{20}$ was likely the first to describe this phenomenon. He described a postural complication observed in

Abbreviations used in this paper: $\mathrm{VB}=$ vertebral body. patients with thoracolumbar scoliosis treated by posterior spinal fusion and placement of Harrington distraction instrumentation. In one patient he performed bilateral pelvic osteotomies to restore upright posture.

In 1976, Moe and Denis ${ }^{53}$ reported on 16 patients with loss of lumbar lordosis after thoracolumbar fusions. They introduced the term flat-back syndrome. Symptoms included muscular pain in the upper back and lower cervical area, pain in the knees, and inability to stand upright. To evaluate the spinal alignment they obtained a full-length standing lateral radiograph of the spine with the patient's knees fully extended. A plumb line was dropped from the center of C-7 and the distance was measured from this line to the sacral promontory; less than $2 \mathrm{~cm}$ was considered normal. Moe and Denis were the first to report correction of lumbar hypolordosis by closing wedge osteotomies through the posterior fusion mass. Although follow up for the 16 patients included in the study was short, initial results were promising. In an attempt to prevent the deformity, they introduced the Moe square-ended rod and hook to allow the rod to be contoured into lordosis while preventing rod rotation. The main emphasis of their report was that flat-back syndrome is preventable. Grobler and coworkers ${ }^{29}$ updated this series with the addition of 13 patients. They reported the results of an extension osteotomy with Harrington compression rods with an average of 26 months follow up. All patients showed improvement; 
however, six patients demonstrated a persistent forward leaning tendency after prolonged activity.

In 1988, Kostuik and associates ${ }^{39}$ reported on combined single-stage anterior and posterior osteotomies in 54 patients to treat iatrogenic flat-back syndrome. In this group of patients, the original fusion was to the sacrum in 44 patients, to L-5 in eight patients, and to L-4 in two patients. No patient in whom fusion stopped at or above L-3 developed flat-back deformity. The same year, La Grone and associates $^{42}$ reviewed the Minneapolis experience. They reported on 66 extension osteotomies performed in 55 patients to treat iatrogenic loss of lumbar lordosis. Failure to restore sagittal plane balance led to a higher rate of pseudarthrosis and recurrent deformity. In 1983 Cochran and associates ${ }^{17}$ reported on 100 patients treated with Harrington rod fusion for idiopathic scoliosis with a minimum 5 -year follow up. They found that in patients who had undergone fusion distal to L-3 their lumbar lordosis was not maintained, many developed retrolisthesis and all had significant low-back pain. Since then several authors have discussed different techniques to correct flat-back syndrome surgically.

\section{CAUSES OF FLAT-BACK SYNDROME}

There is a spectrum of causes that can lead to flat-back syndrome. Several factors have been identified as contributing to the syndrome. They include placement of distraction instrumentation in the lower lumbar spine or sacrum, pseudarthrosis resulting in loss of sagittal plane correction, fixed thoracic hyperkyphosis, hip flexion contractures, and preexisting thoracolumbar kyphosis. ${ }^{42}$

\section{Distraction Instrumentation}

The use of distraction instrumentation in the lower lumbar spine or sacrum is the single biggest risk factor for developing flat-back syndrome. It was not until the use of spinal instrumentation that the complication of flat-back developed. Moskowitz and associates ${ }^{54}$ reported on 61 of 110 patients who had undergone posterior spinal fusion without instrumentation for scoliosis, with more than a 20 -year follow up. None developed symptomatic loss of lordosis.

Distraction instrumentation allowed greater correction to be obtained and maintained in the frontal plane. Initially little consideration was given to the effect of distraction instrumentation on the sagittal plane. When placing posterior distraction instrumentation that is not contoured for lordosis there is a tendency to flatten the lumbar lordosis or even to cause frank kyphosis. The magnitude of loss of lordosis increases the farther distally the instrumentation is placed. Aaro and Ohlen ${ }^{1}$ studied 96 patients in whom Harrington distraction instrumentation had been placed. They used nonradiographic methods (kyphometer inclinometer) and demonstrated a progressive loss of lumbar lordosis as the level of instrumentation extended distally. They recommended avoiding fusion below L-3 unless clinically indicated. Patients in whom instrumentation was placed down to to T-12 had lumbar lordosis of $-38^{\circ}$, whereas patients in whom instrumentation was placed to L-5 had lumbar lordosis of only $-16^{\circ}$. In 1990 , Swank, et al., ${ }^{66}$ reviewed 43 patients in whom radiographs had

\section{G. C. Wiggins, S. L. Ondra, and C. I. Shaffrey}

been obtained before and after placement of Harrington instrumentation in the lumbar spine for scoliosis. Lordosis decreased progressively at lower levels of fusion. The increase in lordosis below the fusion did not compensate for the overall loss of lordosis in the fused portion of the spine.

The incidence of flat-back syndrome varies by study and to a greater extent by the distal level of the distraction instrumentation. In 1981 Swank and associates ${ }^{65}$ reported on 222 adult patients who underwent operations for scoliosis. With an average of 3.9 years of follow up, they noted a 5\% incidence of symptomatic loss of lumbar lordosis. There was no mention of the distal levels of fusion. In 1983, Kostuik and Hall ${ }^{38}$ reviewed the cases of 45 adult patients in whom fusion was performed to the sacrum for scoliosis. Of the patients, 22 (49\%) were noted to have loss of lumbar lordosis. Thirteen $(29 \%)$ underwent corrective osteotomies with improvement in their pain. Their conclusion was to make every effort to preserve the patient's lumbar lordosis. In another study, van Dam and associates $^{70}$ reported on 91 adult patients who underwent Harrington instrumentation for scoliosis. The average follow-up review was 3.5 years. No patient underwent fusion to the sacrum. Some flattening of the lumbar spine was found $\left(10^{\circ}\right.$ or more in $43 \%$ of patients with instrumentation to L-4 or L-5); however, only two of 35 patients developed symptoms. One patient underwent a corrective osteotomy.

In an attempt to prevent the loss of lordosis, squareended Harrington rods (Moe rods) were developed and contoured to retain lumbar lordosis; however, these rods did not prevent the development of flat-back syndrome. Kostuik and $\mathrm{Hall}^{38}$ described the cases of eight of 11 patients in whom instrumentation was placed to the sacrum with Moe rods who developed loss of lumbar lordosis. The authors did note less loss of lordosis when Luque rods and sublaminar wiring were used. The series reported by van Dam, et al., ${ }^{70}$ included descriptions of Moe rods in all but five patients. It must be concluded that the distraction forces are responsible for loss of lordosis despite having a contoured rod designed to resist rotation.

\section{The Contribution of Pseudarthrosis}

Pseudarthrosis may also contribute to postoperative loss of lumbar lordosis. La Grone and associates ${ }^{42}$ noted that $20 \%$ of their patients undergoing corrective osteotomies for flat-back syndrome had pseudarthrosis with progressive loss of sagittal plane balance. Preexisting thoracolumbar kyphosis is another contributing factor to the development of flat-back syndrome. ${ }^{41}$ Usually the thoracolumbar junction is straight. Frequently in lumbar or thoracolumbar scoliosis, the thoracolumbar junction is kyphotic while the lumbar spine compensates by hyperlordosis. If distraction instrumentation is placed, the lumbar spine may not be able to compensate.

\section{Patient Positioning}

The principle cause of loss of lumbar lordosis when using modern transpedicular spinal instrumentation systems is patient positioning that reduces lumbar lordosis. Positions that have been demonstrated to reduce lumbar lordosis include both "knee-chest" and kneeling posi- 
tions. Lumbar lordosis has convincingly been demonstrated to reduce the flexion of the hips that normally occurs with either the knee-chest or kneeling positions such as that used with an Andrews type table (Orthopaedic Systems, Inc., Hayword, CA). ${ }^{3,56}$ Conversely, lumbar lordosis is accentuated when positioning patients with the hips fully extended such as occurs with a Jackson Table (Orthopaedic Systems, Inc.). ${ }^{63}$

\section{Other Causes}

Segmental distraction with transpedicular instrumentation for "foraminal enlargement" or during device or bone graft placement for posterior interbody lumbar fusion or transforaminal interbody lumbar fusion can also induce focal kyphosis. Although the loss of lumbar lordosis may not be as dramatic as was classically seen with Harrington instrumentation, the compensatory mechanisms are less in older patients and flat-back syndrome can still develop.

Patients with loss of lumbar lordosis compensate with hip extension and relative extension of the thoracic spine. Hasday and associates ${ }^{32}$ noted that hip hyperextension is the favored compensatory mechanism. If the patient has either a fixed thoracic kyphosis or hip flexion contractures, they cannot compensate for the loss of lumbar lordosis and will end up in further positive balance.

\section{CLINICAL PRESENTATION}

\section{Patient Symptoms}

Flat-back syndrome is characterized by loss of normal lumbar lordosis resulting in a typical clinical syndrome characterized by 1) forward inclination of the trunk, 2) inability to stand erect without knee flexion, and 3) pain. ${ }^{19}$ Patients require first extension of the hips and then knee flexion and cervical extension to maintain horizontal gaze. Because of the strain of trying to achieve erect posture, pain and fatigue may be noted in the cervical, thoracic, and lumbar spine.

The lumbar spine is at a biomechanical disadvantage. This leads to fatigue as the day progresses. Patients may also complain of anterior thigh pain or knee pain secondary to the constant flexion at the knees that is necessary to maintain forward horizontal gaze. ${ }^{32}$ Physical examination reveals flattening of the lumbar spine with forward tilt of the trunk when the patient is standing with knees fully extended.

Placement of Harrington distraction instrumentation was often stopped at L-4 because the L-5 lamina was not suitable for the distraction hook and the sacrum often did not provide a good anchoring base. Unfortunately, the L4-5 motion segment is one of the most mobile in the lumbar spine. ${ }^{21}$ Disc degeneration and facet joint degeneration develop at this hypermobile L4-5 segment. ${ }^{17}$ This can cause symptoms of neurogenic claudication or L-5 radiculopathy.

\section{Disease Evaluation}

Workup should include obtaining a standing full-length (36-in) lateral radiographic view with the knees fully extended. Optimally, both the C-7 vertebrae and the hip joints will be visualized. A plumb line is dropped from the center of C-7 and the distance is measured from the posterior aspect of the L5-S1 disc space to the plumb line. This will establish the sagittal balance. Flexibility of the curve may be determined by extension studies while the patient is supine with a bolster under the deformity. Magnetic resonance imaging or postmyelography computerized tomography scanning is also helpful to delineate areas of stenosis that may need to be decompressed at the time of correction.

Evaluation should determine if the deformity is fixed or flexible. Clinically, this can be determined by examining the patient in a standing, sitting, and prone hyperextension position. ${ }^{11}$ Patients with fixed thoracic or lumbar deformities will look normal while sitting. While supine the patient's thighs may not touch the table despite the lack of hip disease.

\section{Normal Sagittal Alignment}

Any discussion of deformity regarding sagittal alignment would not be complete without a discussion of "normal" sagittal balance. At birth, the human spine has a kyphotic curvature that encompasses the entire spine. As the child begins to ambulate and develop an upright posture, the spinal column develops a compensatory lordosis in the cervical and lumbar spine. The two lordotic curves balance the thoracic kyphosis resulting in lining the head up over the pelvis.

Propst-Proctor and Bleck ${ }^{57}$ reviewed lateral radiographs obtained in 104 children and found that lumbar lordosis from the top of L-1 to bottom of L-5 averaged $-40^{\circ}$ in normal children and $-48.5^{\circ}$ in those with scoliosis. In adults, the same measurements by Stagnara and associates $^{62}$ demonstrated an average lordosis of $-42^{\circ}$ with a range from -18 to $-69^{\circ}$. When the same patients were measured from the top of L-1 to the top of the sacrum the range changed to between 33 and $79^{\circ}$. In asymptomatic patients older than 40 years of age, Gelb and associates ${ }^{26}$ found that $\mathrm{T} 12-\mathrm{S} 1$ lordosis averaged $-64 \pm 10^{\circ}$. This just confirms a wide range of "normal" lumbar lordosis.

The absolute value of the lumbar lordosis or the thoracic kyphosis is of little significance. What is important clinically is the overall sagittal balance of the spine. ${ }^{41}$ The head should be over the sacrum in both the frontal and sagittal planes. The global sagittal balance can be determined by obtaining a full-length lateral radiograph of the spine with the knees fully extended. A plumb line is dropped from the dens (or the middle of C-7 if the dens is not visualized). Neutral sagittal balance exists when a plumb line dropped from the body of C-7 intersects the posterosuperior corner of the S-1 VB. If the plumb line falls behind the lumbosacral disc, this is negative balance. If the plumb line falls in front of the lumbosacral disc, this is positive sagittal balance. The $\mathrm{C} 7-\mathrm{S} 1$ distance is the distance from this plumb line to the anterior aspect of the sacrum. If the plumb line falls within $2 \mathrm{~cm}$ of the anterior aspect of the sacrum, this is considered normal in patients without scoliosis or in those with idiopathic scoliosis who have not undergone surgery. ${ }^{53}$ Gelb and associates ${ }^{26}$ evaluated 100 asymptomatic volunteers with no history of spinal deformity who were older than 40 years of age. They found the C7-S1 distance to be $3.2 \pm 3.2 \mathrm{~cm}$ behind the sacrum. 


\section{G. C. Wiggins, S. L. Ondra, and C. I. Shaffrey}

\section{PREVENTION}

The surgical treatment of flat-back deformity is an extensive operation that can precipitate perioperative complications in upward of $60 \%$ of patients. ${ }^{42}$ Most patients improve beyond their preoperative status, but few are completely relieved of their symptoms. In their review of surgical correction of flat-back syndrome, La Grone and associates $^{42}$ noted that $47 \%$ of patients complained of leaning forward and $36 \%$ continued to have back pain. These results were reported over an average 6-year follow-up period. Therefore, prevention is the best way to treat this deformity.

Proper patient positioning and avoiding the placement of distraction instrumentation, especially in the lower lumbar spine and sacrum, are the primary methods to alleviate postoperative loss of lumbar lordosis. The use of segmental instrumentation, particularly multisegmental pedicle screw instrumentation systems, has allowed greater maintenance of lumbar lordosis. Bridwell and associates ${ }^{10}$ studied 160 patients treated with segmental instrumentation. They found that this placement of segmental instrumentation to the middle and distal lumbar spine could preserve and, at times, enhance lumbar lordosis. In 1992, Lenke and associates ${ }^{49}$ reported on their experience in 95 patients treated with segmental instrumentation with an average follow up of 35 months. They concluded that this instrumentation helped to preserve segmental lumbar lordosis. In the following year the same group determined that segmental instrumentation allowed maintenance of the sagittal alignment while diminishing the number of lumbar levels that were included in the fusion. ${ }^{48}$ By including fewer distal levels in the fusion, they were able to maintain more distal levels to allow compensation for any fusion level loss of sagittal balance. Takahashi and associates ${ }^{67}$ retrospectively reviewed 30 patients with 5 to 9 years follow up after the placement of Cotrel-Dubousset instrumentation for idiopathic scoliosis. They found a gradual increase in lumbar lordosis below the lowest instrumented vertebra, thereby maintaining sagittal alignment.

There is an increasing incidence of loss of lumbar lordosis as the fusion extends distally to the sacrum. ${ }^{38,42}$ If fusion to the sacrum is determined to be necessary, placement of distraction instrumentation should be avoided. Alternative forms of instrumentation include the Galveston technique of inserting L-rods into the pelvis and pedicle screw fixation. Deciding on the proximal end of the fusion is also important. If the fusion is stopped at or just below the apex of the thoracic or thoracolumbar kyphosis, there is a risk of "falling off" proximal to the fusion. ${ }^{41}$ This would tend to increase the kyphosis and increase the problem of loss of sagittal balance. By extending the proximal fusion above the apex of the kyphosis, this complication can be avoided.

\section{TREATMENT}

The first line of management is nonoperative. This includes exercises to increase hip and back extension, nonsteroidal antiinflammatory medicine, and bracing. Patients should be evaluated for the presence of hip flexion contractures and if present, they should be aggressively treated. Once the patient becomes symptomatic, nonoperative management has generally not proved to be successful. ${ }^{42}$ If the symptoms persist despite conservative therapy or if the sagittal imbalance is progressive, surgical treatment is indicated.

\section{Surgical Planning}

The goal of surgery is to restore the sagittal balance such that the plumb line intersects the posterosuperior corner of the S-1 vertebra, in other words, to end up with the head centered over the sacrum. This will allow the patient to stand without knee flexion and hip hyperextension, thereby diminishing the overall pain.

The decision regarding where to place the osteotomy depends on the site of the deformity. Patients with flattening of the lumbar spine without thoracolumbar kyphosis can be treated by osteotomies below the level of the conus medullaris. This provides adequate lordosis without jeopardizing the spinal cord. If there is coexisting thoracolumbar kyphosis, this also needs to be addressed. If it is flexible and correction can be seen on hyperextension radiographs, osteotomies can be performed in the lumbar spine and the fusion can be extended proximally into the thoracic spine. If it is not flexible, either an osteotomy can be performed at the apex of the kyphosis (usually thoracolumbar junction) or an osteotomy of larger magnitude or multiple levels of osteotomies can be performed.

There have been several types of osteotomies described to correct sagittal imbalance. Extension (Smith-Petersen), polysegmental, and closing wedge osteotomies have all been described to treat fixed sagittal deformities. Many of these types of osteotomy were initially described to treat deformity secondary to ankylosing spondylitis and have

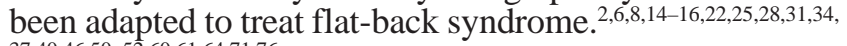
$37,40,46,50-52,60,61,64,71,76$

\section{Extension (Smith-Petersen) Osteotomy}

In 1945, Smith-Petersen and associates ${ }^{61}$ were the first to describe a posterior osteotomy for correction of fixed sagittal deformity in patients with rheumatoid arthritis. The osteotomy involves removing the posterior elements, undercutting the adjacent spinous processes, and then closing the osteotomy thus creating an opening of the spine (extension) anteriorly through the disc space (Fig. $1)$. The posterior aspect of the disc space is the axis of rotation. The extension osteotomy creates hyperextension by closing the posterior elements and opening the anterior elements. In 1946, La Chapelle ${ }^{40}$ described a modification of the technique by adding an anterior release. The anterior release was performed as a second operation and included packing of tibial bone into the disc space.

Authors of various series report the use of extension osteotomies, mainly in the treatment of ankylosing spondylitis. $2,13,22,24,28,34,39,40,43-45,50-52,60,61$ Although extension osteotomy can correct the deformity, the technique does carry the risk of significant morbidity and mortality. By lengthening the anterior column, there is risk of injury to anterior vascular structures and neural elements. In 1959, Law $^{43}$ reported on his experience in 100 patients of whom 80 were available for review. Eight patients (10\%) died of complications related to the procedure. Neurological complications have been reported in up to $30 \%$ of patients. ${ }^{43,51}$ 

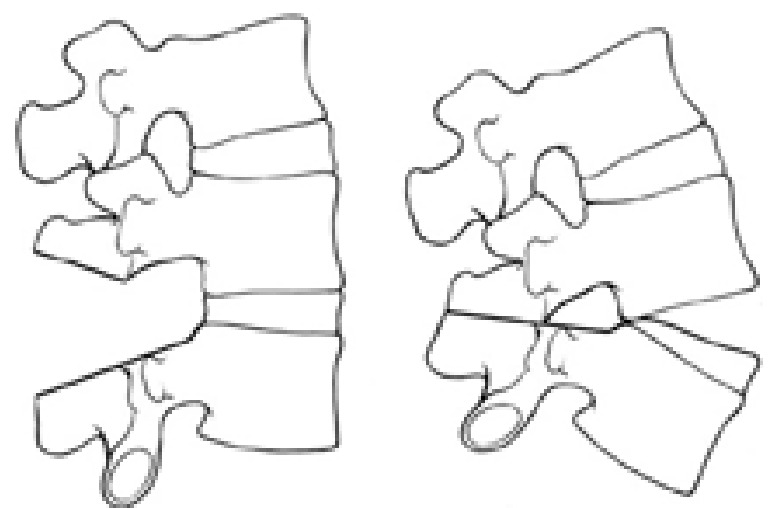

Fig. 1. Line drawing showing an extension (Smith-Petersen) osteotomy. Note that the correction is obtained through rupture of the anterior longitudinal ligament, thus lengthening the anterior spine.

Forceful hyperextension of the spine may cause rupture of the aorta or inferior vena cava, which are frequently calcified in patients with ankylosing spondylitis..$^{50,75}$ As the anterior spine is lengthened, the superior mesenteric artery can stretch over the third part of the duodenum and lead to acute dilation of the stomach and paralytic ileus in the early postoperative period. ${ }^{52,60}$ This results in an increased incidence of emesis and aspiration.

Pseudarthrosis is another reported complication. The osteotomy creates a gap through the disc space. In a standing position, 80 to $90 \%$ of axial compressive forces pass through the anterior lumbar column and only 10 to $20 \%$ pass through the posterior column. ${ }^{4}$ This makes the extension osteotomy biomechanically unstable. In 1947, Briggs and associates ${ }^{13}$ added a spinous process plate to aid in postoperative stability of the spine. In 1985, McMaster ${ }^{51}$ reported the addition of Harrington compression hooks to secure the osteotomy. In 1995, Weale and associates ${ }^{74}$ described the addition of transpedicular screws and cable in 37 patients. They noted a loss of correction of $15^{\circ}$ in the patients in whom there was no fixation and $4.8^{\circ}$ in the patients in whom there was internal fixation. Some authors suggest a simultaneous or staged anterior fusion to help reduce the pseudarthrosis rate.$^{39-42}$

The extension osteotomy can achieve a significant degree of correction at one level. The reported average correction in most series is approximately $32^{\circ} .^{24,28,39,42,51,74}$ The general rule is $1^{\circ}$ of correction for every $1 \mathrm{~mm}$ of bone resected posteriorly. ${ }^{9}$ Unfortunately the correction is lost over time. McMaster ${ }^{51}$ reported a $5^{\circ}$ loss of correction over 3 years even in patients who wore a plaster jacket postoperatively. La Grone and associates ${ }^{42}$ also reported a $5^{\circ}$ loss of correction over 6 years despite the addition of Harrington compression rods. With the addition of a pedicle screw and cable system, Weale and associates ${ }^{74}$ also reported a mean loss of $4.8^{\circ}$. This is despite revision in several of their patients because of loss of correction within 4 weeks of operation.

Overall, extension osteotomy can correct the sagittal plane deformity. The procedure inherently lengthens the anterior spine and places vascular and neural structures at risk. Additionally, the spine is relatively unstable after this procedure resulting in pseudarthrosis and loss of correction.

\section{Polysegmental Osteotomies}

Extension osteotomies produce correction by creating a sharp lordotic angle and elongation of the anterior column that may result in significant complications. In 1949 , Wilson and Turkell ${ }^{76}$ reported on the use of multiple osteotomies to correct the sagittal balance in a patient with ankylosing spondylitis. This was achieved through polysegmental posterior lumbar osteotomies (Fig. 2). This technique involves removing the facet joints at several levels and then compressing the posterior elements to create a lordosis. The correction is obtained through the deformation of the disc spaces without rupture of the anterior longitudinal ligament.

Several authors advocate polysegmental lumbar osteotomies to create a harmonious lumbar lordosis. ${ }^{16,31,33}$, 58,72,76 Wilson and Turkell ${ }^{76}$ first reported the use of osteotomies alone. Simmons ${ }^{60}$ added the use of internal fixation (Harrington compression rod) to thoracic posterior wedge osteotomies and an anterior strut. This device failed in the lumbar spine. ${ }^{8,31,58}$ In 1990, Hehne and associates $^{33}$ reported on their experience in 177 patients with ankylosing spondylitis treated with polysegmental lumbar osteotomies by using transpedicular screw and threaded rods. The average correction was $44^{\circ}$, approximately $9.5^{\circ}$ per segment. Complications include $2.3 \%$ mortality, $2.3 \%$ nonreversible neurological deficit, and $18 \%$ reversible complications. Despite the use of postoperative body casts, there was an average loss of $20 \%$ of the correction with implant breakage in four patients.

Using a similar method in 1998 , Chen ${ }^{16}$ reported his experience with 16 patients. The average correction was $25.8^{\circ}$ or $5^{\circ}$ per segment. The average loss of correction was $0.9^{\circ}$ per segment with early rod breakage in $25 \%$ of patients. In 1988, van Royen and associates ${ }^{72}$ reported on their experience with 21 patients. They achieved an average curve improvement of $25.6^{\circ}, 9.5^{\circ}$ per segment, and mean loss of $10.7^{\circ}$ over the whole fusion. Forty-three percent of their patients had a postoperative complication. Insufficient correction or loss of correction led to implant failure.
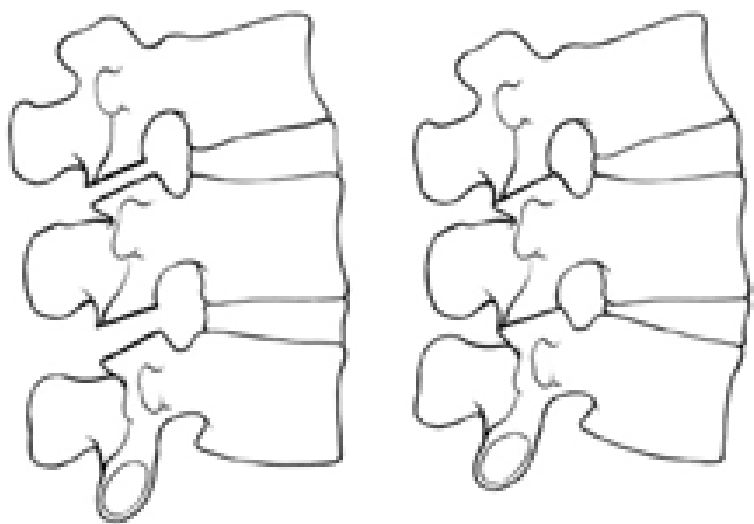

Fig. 2. Line drawing showing a polysegmental osteotomy. The correction is obtained through disc deformation without rupture and compression of the osteotomy with instrumentation. 


\section{Closing Wedge Osteotomy}

A closing wedge osteotomy is the next technique described to correct the deformity without lengthening the anterior spine. In 1963, Scudese and Calabro ${ }^{59}$ were the first to describe a monosegmental intravertebral closing wedge posterior osteotomy of the lumbar spine. Later, Thomasen ${ }^{69}$ reported on 11 patients with ankylosing spondylitis treated with posterior closing wedge osteotomies. $\mathrm{He}$ used spinous process plates in four patients and spinous process wiring in two. A closing wedge osteotomy (Fig. 3) involves the complete removal of a wedge of bone with the base at the spinous processes and the apex at the anterior margin of the VB. Care is taken to undercut the dorsal elements adequately at the levels above and below the primary osteotomy level to ensure that the neural elements are not constricted. A version of the closing wedge osteotomy, described as the pedicle subtraction osteotomy, has gained popularity in correcting significant sagittal plane and coronal plane deformities. This aggressive osteotomy involves the removal of the posterior elements including the pedicle and transverse process. With this technique, removal of up to $6 \mathrm{~cm}$ of bone is possible with resultant sagittal plane correction of up to $60^{\circ}$. By performing an asymmetrical removal of the posterior elements, correction of both sagittal and coronal plane deformities can be performed (Figs. 4 and 5).

This procedure is technically demanding and substantial blood loss typically occurs from the epidural venous plexus or from the cancellous bone surfaces. With the removal of the pedicle bilaterally, two nerve roots exit through the reconstructed neural foramina at the level of the osteotomy. Care must be taken during the closure of the osteotomy that impingement of the thecal sac or nerve roots does not occur.

Since the original description there have been many reports on using these techniques for fixed sagittal plane deformities of different types, ranging from ankylosing spondylitis to trauma to flat-back deformity. $5,12,14,15,18,23,27$, $30,35-37,46,47,55,68,69,73$ In a recent report by Bridwell and associates $^{12} 27$ patients with fixed sagittal imbalance treated with pedicle subtraction closing wedge osteotomy were
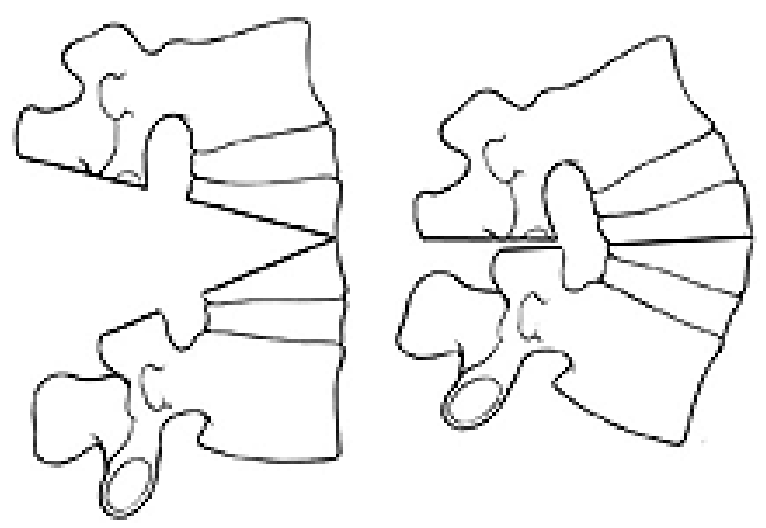

Fig. 3. Line drawing showing a closing wedge osteotomy. The axis of rotation is the anterior margin of the VB. This osteotomy places two large cancellous surfaces together to achieve fusion. Note that two nerve roots will now exit through one larger neural foramen.

\section{G. C. Wiggins, S. L. Ondra, and C. I. Shaffrey}

reviewed. The causes were varied (14 idiopathic scoliosis, eight degenerative scoliosis, three posttraumatic, and two ankylosing spondylitis). The average immediate postoperative correction was $33.5^{\circ}$ and $34.5^{\circ}$ at a minimum of 2year follow-up evaluation. Sagittal plumb line improved from $17.74 \mathrm{~cm}$ to $1.99 \mathrm{~cm}$ immediately postoperatively and to $4.23 \mathrm{~cm}$ on final follow up. Twenty-four complications occurred in these 27 patients.

There are several advantages of pedicle subtraction closing wedge osteotomy. Correction is obtained through all three columns of the spine. This allows for correction in both the sagittal and coronal plane. By respecting more bone on the convexity of the deformity, coronal deformities can also be corrected at the same level. ${ }^{12}$ In addition, the spine is not lengthened, thereby avoiding the vascular and abdominal complications associated with extension osteotomies. The bone surface for fusion is large and placed under compression by the mechanics of the osteotomy. The instrumentation is therefore used to maintain the alignment as opposed to creating the desired alignment.

\section{Comparison of Techniques}

In 1999, Van Royen and De Gast ${ }^{71}$ performed a metaanalysis of data obtained from the literature to compare opening wedge, polysegmental, and closing wedge osteotomies in the treatment of ankylosing spondylitis. They included 41 articles describing 856 patients reported on between 1945 and 1998. Only 16 studies involving 523 patients met the inclusion criteria. Perioperative mortality was highest in opening wedge osteotomies (5.8\%) and lowest in closing wedge osteotomies $(1.3 \%)$. Neurapraxia was reported in $11.3 \%$ of polysegmental osteotomies and $7.8 \%$ of closing wedge osteotomies. As the polysegmental osteotomies are closed, the neural foramen is narrowed and can create new radiculopathy. Additionally, paralysis was seen in $3.1 \%$ of opening wedge osteotomies, $2 \%$ of polysegmental osteotomies, and did not occur in closing wedge osteotomies.

In 330 of the patients the degree of surgical correction was reported. The average correction was similar (35$40^{\circ}$ ) for each technique; however, there was significantly more loss of correction in both opening wedge osteotomy (3.9\%) and polysegmental osteotomy $(6 \%)$ than in the closing wedge osteotomy (2.7\%). Outcome results were similar, with good outcomes ranging from 69 to $78 \%$. The authors decided that there was insufficient evidence to conclude that one surgical technique is preferable to the other. There was, however, a trend toward less serious complications in closing wedge osteotomy with greater maintenance of correction.

Booth and associates ${ }^{7}$ reviewed a consecutive series of flat-back deformity in 28 patients. They had a minimum of 2 years of follow up with an average of 3.6 years. Three patients had extension osteotomies alone, three patients had closing wedge osteotomies alone, and the remainder underwent a variety of anterior and posterior procedures. All patients underwent placement of hook-rod-screw systems. There were seven patients with 11 complications. There were no deaths, and no patient suffered a neurological deficit. All the complications occurred in patients who underwent anterior and posterior procedures. All patients completed outcome questionnaires. Seventy-nine percent 


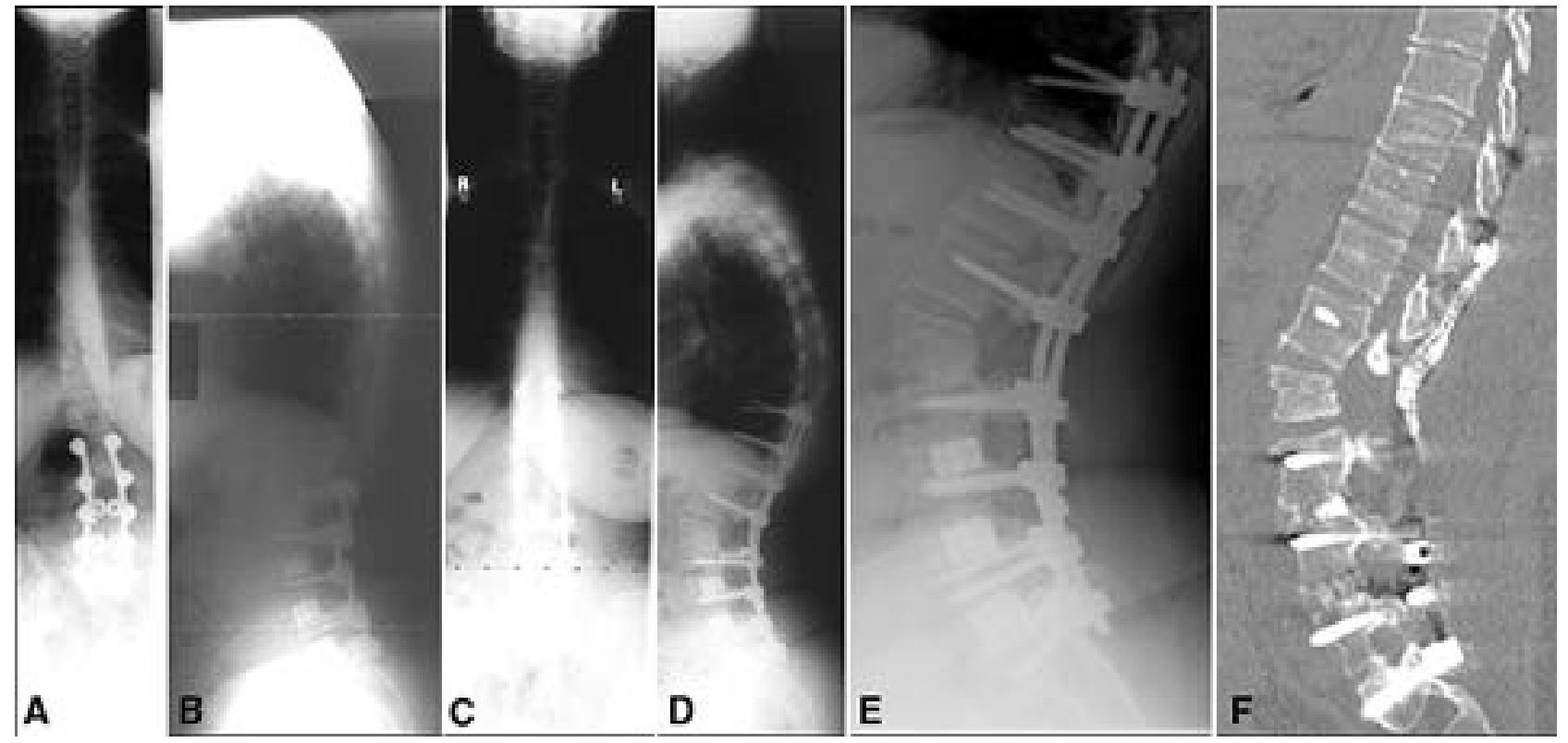

Fig. 4. Anteroposterior (A) and lateral (B) radiographs obtained in a 40-year-old patient who underwent a laminectomy, posterior lumbar interbody fusion, and then an instrumented fusion. Note the positive sagittal balance with a mild lumbar scoliosis. She had severe back pain and an inability to stand erect for more than 10 minutes. The patient underwent pedicle subtraction osteotomy at L-2 with extension of her fusion. Postoperative anteroposterior (C), lateral (D), and lumbar lateral (E) radiographs demonstrating correction of the lumbar scoliosis and restoration of sagittal balance. Sagittal reconstruction $(\mathrm{F})$ of a computerized tomography scan demonstrates the closure of the osteotomy and sagittal correction.
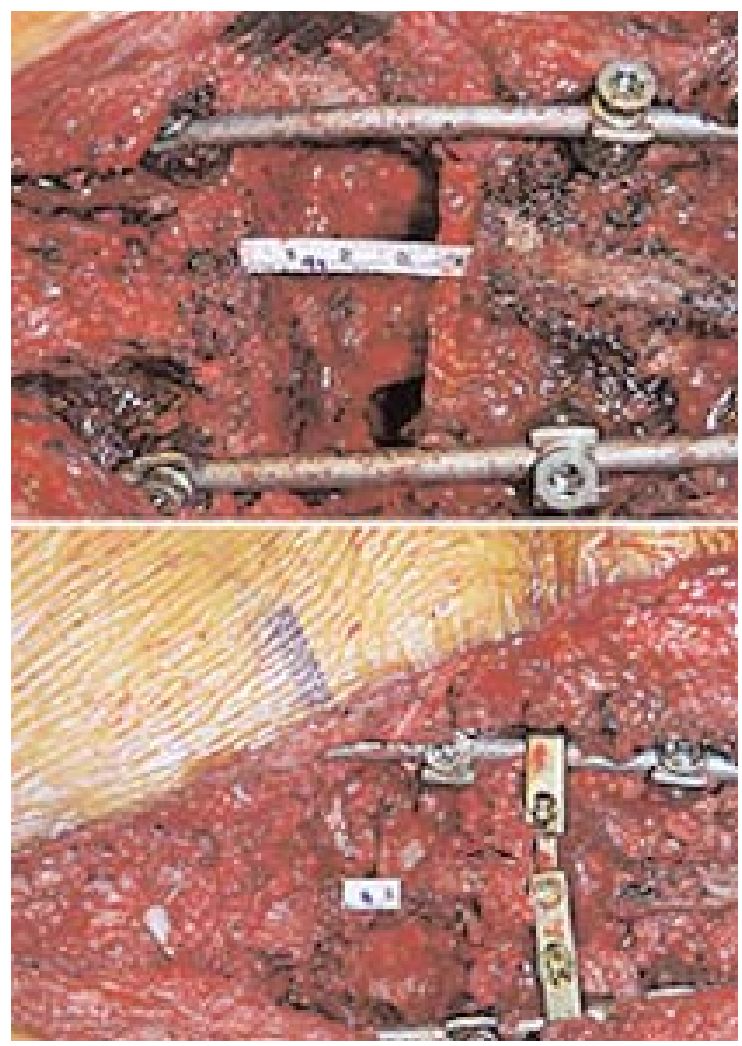

Fig. 5. Preclosure (A) and postclosure (B) intraoperative photographs obtained in the patient in Fig. 4 demonstrate the amount of closure obtained at the osteotomy. reported a decrease in pain as a result of the procedure; $50 \%$ reported increased function. Although the numbers are small, this study demonstrates good outcomes for patients who underwent surgical correction of flat-back syndrome.

\section{CONCLUSIONS}

Iatrogenic flat-back syndrome usually develops after long-segment thoracolumbar instrumentation and fusion. This is especially common after placement of distractive instrumentation extending to the lumbosacral junction. Now with long-term follow up available for patients who have undergone fusion and instrumentation for scoliosis, flat-back syndrome is often recognized. Patients typically present with the inability to stand erect without flexing the knees or hyperextending the hips. This leads to chronic back pain. Workup should include a long cassette lateral spine radiograph of the patient standing with his or her knees and hips fully extended. Surgical correction can include extension (Smith-Petersen) osteotomy, polysegmental osteotomies, closing wedge osteotomy, or a combined anterior-posterior surgery. The amount of correction is similar with each procedure, but serious complications are more frequent with the extension osteotomy. Prevention is the most important factor in treating flatback syndrome.

\section{Disclaimer}

The views expressed are those of the authors and do not reflect the official policy or position of the US Government, the Department of Defense, or the Department of the Air Force. 


\section{References}

1. Aaro S, Ohlen G: The effect of Harrington instrumentation on the sagittal configuration and mobility of the spine in scoliosis. Spine 8:570-575, 1983

2. Adams JC: Technique, dangers, and safeguards in osteotomy of the spine. J Bone Joint Surg Br 34:226-232, 1952

3. Benfanti PL, Geissele AE: The effect of intraoperative hip position on maintenance of lumbar lordosis: a radiographic study of anesthetized patients and unanesthetized volunteers on the Wilson frame. Spine 22:2299-2303, 1997

4. Bergmark A: Stability of the lumbar spine. A study in mechanical engineering. Acta Orthop Scand Suppl 230:1-54, 1989

5. Berven SH, Deviren V, Smith JA, et al: Management of fixed sagittal plane deformity: results of the transpedicular wedge resection osteotomy. Spine 26:2036-2043, 2001

6. Boachie-Adjei O, Bradford DS: Vertebral column resection and arthrodesis for complex spinal deformities. J Spinal Disord 4:193-202, 1991

7. Booth KC, Bridwell KH, Lenke LG, et al: Complications and predictive factors for the successful treatment of flatback deformity (fixed sagittal imbalance). Spine 24:1712-1720, 1999

8. Bradford DS, Schumacher WL, Lonstein JE, et al: Ankylosing spondylitis: experience in surgical management of 21 patients. Spine 12:238-243, 1987

9. Bridwell KH: Osteotomies for fixed deformities in the thoracic and lumbar spine, in Bridwell KH, DeWald RL (eds): The Textbook of Spinal Surgery, ed 2. Philadelphia: LippincottRaven, 1997, pp 821-835

10. Bridwell KH, Betz R, Capelli AM, et al: Sagittal plane analysis in idiopathic scoliosis patients treated with Cotrel-Dubousset instrumentation. Spine 15:644-649, 1990

11. Bridwell KH, Lenke LG, Lewis SJ: Treatment of spinal stenosis and fixed sagittal imbalance. Clin Orthop 384:35-44, 2001

12. Bridwell KH, Lewis SJ, Lenke LG, et al: Pedicle subtraction osteotomy for the treatment of fixed sagittal imbalance. J Bone Joint Surg Am 85454-463, 2003

13. Briggs H, Keats S, Schlesinger PT: Wedge osteotomy of the spine with bilateral intervertebral foraminotomy: correction of flexian deformity in five cases of ankylosing arthritis of spine. J Bone Joint Surg 29:1075-1082, 1947

14. Camargo FP, Cordeiro EN, Napoli MM: Corrective osteotomy of the spine in ankylosing spondylitis. Experience with 66 cases. Clin Orthop 208: 157-167, 1986

15. Chen IH, Chien JT, Yu TC: Transpedicular wedge osteotomy for correction of thoracolumbar kyphosis in ankylosing spondylitis: experience with 78 patients. Spine 26: E354-360, 2001

16. Chen PQ: Correction of kyphotic deformity in ankylosing spondylitis using multiple spinal osteotomy and Zielke's VDS instruments. Taiwan Yi Xue Hui Za Zhi 87:692-699, 1988

17. Cochran T, Irstam L, Nachemson A: Long-term anatomic and functional changes in patients with adolescent idiopathic scoliosis treated by Harrington rod fusion. Spine 8:576-584, 1983

18. Danisa OA, Turner D, Richardson WJ: Surgical correction of lumbar kyphotic deformity: posterior reduction "eggshell" osteotomy. J Neurosurg (Spine 1) 92:50-56, 2000

19. DeWald RL: Revision surgery for spinal deformity. Instr Course Lect 41:235-250, 1992

20. Doherty JH: Complications of fusion in lumbar scoliosis. J Bone Joint Surg Am 55:438, 1973 (Abstract)

21. Dvorak J, Panjabi MM, Chang DG, et al: Functional radiographic diagnosis of the lumbar spine. Flexion-extension and lateral bending. Spine 16:562-571, 1991

22. Emneus H: Wedge osteotomy of spine in ankylosing spondylitis. Acta Orthop Scand 39:321-326, 1968

23. Farcy JP, Schwab F: Posterior osteotomies with pedicle substraction for flat back and associated syndromes. Technique and results of a prospective study. Bull Hosp Jt Dis 59:11-16, 2000
G. C. Wiggins, S. L. Ondra, and C. I. Shaffrey

24. Farcy JP, Schwab FJ: Management of flatback and related kyphotic decompensation syndromes. Spine 22:2452-2457, 1997

25. Fazl M, Bilbao JM, Hudson AR: Laceration of the aorta complicating spinal fracture in ankylosing spondylitis. Neurosurgery 8:732-734, 1981

26. Gelb DE, Lenke LG, Bridwell KH, et al: An analysis of sagittal spinal alignment in 100 asymptomatic middle and older aged volunteers. Spine 20:1351-1358, 1995

27. Gertzbein SD, Harris MB: Wedge osteotomy for the correction of post-traumatic kyphosis. A new technique and a report of three cases. Spine 17:374-379, 1992

28. Goel MK: Vertebral osteotomy for correction of fixed flexion deformity of the spine. J Bone Joint Surg Am 50:287-294, 1968

29. Grobler LJ, Moe JH, Winter RB: Loss of lumbar lordosis following surgical correction of thoracolumbar deformities. Orthop Trans 2:239, 1978

30. Guven O, Bezer M, Gokkus K, et al: Transpedicular decancellation osteotomy in the treatment of peridural fibrosis. Arch Orthop Trauma Surg 121:517-520, 2001

31. Halm H, Metz-Stavenhagen P, Zielke K: Results of surgical correction of kyphotic deformities of the spine in ankylosing spondylitis on the basis of the modified arthritis impact measurement scales. Spine 20:1612-1619, 1995

32. Hasday CA, Passoff TL, Perry J: Gait abnormalities arising from iatrogenic loss of lumbar lordosis secondary to Harrington instrumentation in lumbar fractures. Spine 8:501-511, 1983

33. Hehne HJ, Zielke K, Bohm H: Polysegmental lumbar osteotomies and transpedicled fixation for correction of longcurved kyphotic deformities in ankylosing spondylitis. Report on 177 cases. Clin Orthop 258:49-55, 1990

34. Herbert JJ: Vertebral osteotomy for kyphosis, especially in Marie-Strumpell arthritis. J Bone Joint Surg Am 41:291-302, 1959

35. Jaffray D, Becker V, Eisenstein S: Closing wedge osteotomy with transpedicular fixation in ankylosing spondylitis. Clin Orthop 279:122-126, 1992

36. Kawahara N, Tomita K, Baba H, et al: Closing-opening wedge osteotomy to correct angular kyphotic deformity by a single posterior approach. Spine 26:391-402, 2001

37. Kim KT, Suk KS, Cho YJ, et al: Clinical outcome results of pedicle subtraction osteotomy in ankylosing spondylitis with kyphotic deformity. Spine 27:612-618, 2002

38. Kostuik JP, Hall BB: Spinal fusions to the sacrum in adults with scoliosis. Spine 8:489-500, 1983

39. Kostuik JP, Maurais GR, Richardson WJ, et al: Combined single stage anterior and posterior osteotomy for correction of iatrogenic lumbar kyphosis. Spine 13:257-266, 1988

40. La Chapelle EH: Osteotomy of the lumbar spine for correction of kyphosis in a case of ankylosing spondylarthritis. J Bone Joint Surg 28:851-858, 1946

41. La Grone MO: Loss of lumbar lordosis. A complication of spinal fusion for scoliosis. Orthop Clin North Am 19:383-393, 1988

42. La Grone MO, Bradford DS, Moe JH, et al: Treatment of symptomatic flatback after spinal fusion. J Bone Joint Surg Am 70: 569-580, 1988

43. Law WA: Lumbar spinal osteotomy. J Bone Joint Surg Br 41: 270-278, 1959

44. Law WA: Osteotomy of the spine. Clin Orthop 66:70-76, 1969

45. Law WA: Surgical treament of rheumatic diseases. J Bone Joint Surg Br 34:215-225, 1952

46. Lazennec JY, Saillant G, Saidi K, et al: Surgery of the deformities in ankylosing spondylitis: our experience of lumbar osteotomies in 31 patients. Eur Spine J 6:222-232, 1997

47. Lehmer SM, Keppler L, Biscup RS, et al: Posterior transvertebral osteotomy for adult thoracolumbar kyphosis. Spine 19: 2060-2067, 1994 
48. Lenke LG, Bridwell KH, Baldus C, et al: Ability of CotrelDubousset instrumentation to preserve distal lumbar motion segments in adolescent idiopathic scoliosis. J Spinal Disord 6:339-350, 1993

49. Lenke LG, Bridwell KH, Baldus C, et al: Cotrel-Dubousset instrumentation for adolescent idiopathic scoliosis. J Bone Joint Surg Am 74:1056-1067, 1992

50. Lichtblau PO, Wilson PD: Possible mechanism of aortic rupture in orthopaedic correction of rhematoid spondylitis. J Bone Joint Surg Am 38:123-127, 1956

51. McMaster MJ: A technique for lumbar spinal osteotomy in ankylosing spondylitis. J Bone Joint Surg Br 67:204-210, 1985

52. McMaster MJ, Coventry MB: Spinal osteotomy in akylosing spondylitis. Technique, complications, and long-term results. Mayo Clin Proc 48:476-486, 1973

53. Moe JH, Denis F: The iatrogenic loss of lumbar lordosis. Orthop Trans 1:131, 1977

54. Moskowitz A, Moe JH, Winter RB, et al: Long-term follow-up of scoliosis fusion. J Bone Joint Surg Am 62:364-376, 1980

55. Murrey DB, Brigham CD, Kiebzak GM, et al: Transpedicular decompression and pedicle subtraction osteotomy (eggshell procedure): a retrospective review of 59 patients. Spine 27: 2338-2345, 2002

56. Peterson MD, Nelson LM, McManus AC, et al: The effect of operative position on lumbar lordosis. A radiographic study of patients under anesthesia in the prone and 90-90 positions. Spine 20:1419-1424, 1995

57. Propst-Proctor SL, Bleck EE: Radiographic determination of lordosis and kyphosis in normal and scoliotic children. J Pediatr Orthop 3:344-346, 1983

58. Puschel J, Zielke K: [Corrective surgery for kyphosis in bekhterev's disease-indication, technique, results (author's transl).] Z Orthop Ihre Grenzgeb 120:338-342, 1982

59. Scudese VA, Calabro JJ: Vertebral wedge osteotomy. Correction of rhematoid (ankylosing) spondylitis. JAMA 186: 627-631, 1963

60. Simmons EH: Kyphotic deformity of the spine in ankylosing spondylitis. Clin Orthop 128:65-77, 1977

61. Smith-Petersen MN, Larson CB, Aufranc OE: Osteotomy of the spine for corretion of flexion deformity in rheumatoid arthritis. Cin Orthop 66:6-9, 1969

62. Stagnara P, De Mauroy JC, Dran G, et al: Reciprocal angulation of vertebral bodies in a sagittal plane: approach to references for the evaluation of kyphosis and lordosis. Spine 7:335-342, 1982

63. Stephens GC, Yoo JU, Wilbur G: Comparison of lumbar sagittal alignment produced by different operative positions. Spine 21:1802-1807, 1996
64. Styblo K, Bossers GT, Slot GH: Osteotomy for kyphosis in ankylosing spondylitis. Acta Orthop Scand 56:294-297, 1985

65. Swank S, Lonstein JE, Moe JH, et al: Surgical treatment of adult scoliosis. A review of two hundred and twenty-two cases. J Bone Joint Surg Am 63:268-287, 1981

66. Swank SM, Mauri TM, Brown JC: The lumbar lordosis below Harrington instrumentation for scoliosis. Spine 15:181-186, 1990

67. Takahashi S, Delecrin J, Passuti N: Changes in the unfused lumbar spine in patients with idiopathic scoliosis. A 5- to 9-year assessment after cotrel-dubousset instrumentation. Spine 22: 517-524, 1997

68. Thiranont N, Netrawichien P: Transpedicular decancellation closed wedge vertebral osteotomy for treatment of fixed flexion deformity of spine in ankylosing spondylitis. Spine 18: 2517-2522, 1993

69. Thomasen E: Vertebral osteotomy for correction of kyphosis in ankylosing spondylitis. Clin Orthop 194:142-152, 1985

70. van Dam BE, Bradford DS, Lonstein JE, et al: Adult idiopathic scoliosis treated by posterior spinal fusion and Harrington instrumentation. Spine 12:32-36, 1987

71. Van Royen BJ, De Gast A: Lumbar osteotomy for correction of thoracolumbar kyphotic deformity in ankylosing spondylitis. A structured review of three methods of treatment. Ann Rheum Dis 58:399-406, 1999

72. van Royen BJ, de Kleuver M, Slot GH: Polysegmental lumbar posterior wedge osteotomies for correction of kyphosis in ankylosing spondylitis. Eur Spine J 7:104-110, 1998

73. van Royen BJ, Slot GH: Closing-wedge posterior osteotomy for ankylosing spondylitis. Partial corporectomy and transpedicular fixation in 22 cases. J Bone Joint Surg Br 77:117-121, 1995

74. Weale AE, Marsh CH, Yeoman PM: Secure fixation of lumbar osteotomy. Surgical experience with 50 patients. Clin Orthop 321:216-222, 1995

75. Weatherley C, Jaffray D, Terry A: Vascular complications associated with osteotomy in ankylosing spondylitis: a report of two cases. Spine 13:43-46, 1988

76. Wilson MJ, Turkell JH: Multiple spinal wedge osteotomy. Its use in a case of Marie-Strumpell spondylitis. Am J Surg 77: 777-782, 1949

Manuscript received June 8, 2003.

Accepted in final form August 7, 2003.

Address reprint requests to: Gregory C. Wiggins, M.D., David Grant Medical Center, Neurological Surgery, 60 MSGS/SGCXN, 101 Bodin Circle, Travis Air Force Base, California. 94535-1800. email: greg.wiggins@60mdg.travis.af.mil. 